\title{
THE DEPLOYMENT OF VIRTUAL REALITY (VR) TO PROMOTE GREEN BURIAL
}

\author{
Yui Yip Lau', YM Tang2, Ivy Chan', Adolf K.Y. Ng33, Alan Leung 4 \\ 1. Divison of Business and Hospitality Management, College of Professional and Continuing Education, The Hong Kong \\ Polytechnic University \\ 2. Department of Industrial and Systems Engineering, The Hong Kong Polytechnic University \\ 3. Department of Supply Chain Management, Asper School of Business, University of Manitoba, Canada \\ 4. Faculty of Business, Law and Tourism, Sunderland University
}

Correspondence: yuiyip.lau@cpce-polyu.edu.h

\begin{abstract}
Population projections for Hong Kong suggest that the city will accommodate 8.22 million people in 2043. One in every three people are expected to be older than 65 in 2066. The long-held Chinese traditions for burial of deceased with reverence and honour, coupled with the chronic land shortage have presented an excessive demand for cemetery space. Niches are seldom recycled, and the inadequate supply of new columbarium niche requires the family of the deceased to consider an alternative way for keeping cremated ashes. To ease the demand, "green burial" has been launched and promoted by the HKSAR government through different print and social media. Currently, scattering of cremains in Gardens of Remembrance or at sea are the two common ways to perform green burial. The public acceptance of green burial is still questionable and is under-researched.
\end{abstract}

This study is going to deploy innovative technology, virtual reality (VR) to increase physical and psychological fidelity in highly resembled scenarios for the people. On one hand, VR gives immeasurable value to people when they are enabled to navigate different circumstances (physical fidelity) before considering the use of green burial. On the other hand, VR enables the people to engage in different mental processes (psychological fidelity) replicated from an array of cognitive reaction and sentiments with the choice of green burial. In order to optimize the configuration of the VR settings, we will conduct a face-toface, semi-structured and in-depth interview with different practitioners. In the study, we explore: (1) To what extent the enhancement of physical fidelity of innovative technologies debunk public's misconception of green burial? (2) To what extent the enhancement of psychological fidelity of innovative technologies debunk public's misconception of green burial? (3) To what extent the simulated experience derived from innovation technologies change the public acceptance of green burial?

\section{KEYWORDS}

green burial; virtual reality; physical fidelity; psychological fidelity

\section{INTRODUCTION}

In Hong Kong, the current population has almost reached 7.4 million. The population growth rate will be at $0.6 \%$ in the forthcoming years. By 2043, the population in Hong Kong is expected to reach a peak of 8.22 million. We expect that elderly persons will make up around $30 \%$ of the total Hong Kong population. [1] The male life expectancy will 
significantly increase from 67.8 years old in 1971 to 87.1 years old in 2066. The expectation for female life expectancy will also rise from 75.3 years old in 1971 to 93.1 years old in 2066. This dramatic growth of aging population is a severe challenge. With the population ageing along with unexpected infectious disease will lead to a number of deaths and the overall mortality rates will exhibit a rising trend in the forthcoming years. [2, 3] The long-held Chinese traditions for burial of deceased as reverence and honour, coupled with the chronic land shortage have presented an excessive demand for cemetery space. In addition, niches are seldom recycled, and the inadequate supply of new columbarium niche forces the family of the deceased to consider alternative ways for keeping cremated ashes. In the past few decades, the number of cemeteries in Hong Kong has remained the same. Clearly, the numbers of cemeteries are insufficient to meet the future demand. The situation of handling the deceased has reached a bottleneck. The number of deaths and cemeteries in Hong Kong are listed in Table 1.

TABLE 1: NUMBER OF DEATHS AND CEMETERIES IN HONG KONG (2014-2018)

\begin{tabular}{|l|l|l|l|l|l|}
\hline & 2014 & 2015 & 2016 & 2017 & 2018 \\
\hline Number of deaths & 45087 & 46108 & 46905 & 46829 & 47400 \\
\hline Public cemeteries & 8 & 8 & 8 & 8 & 8 \\
\hline Private cemeteries & 30 & 30 & 30 & 30 & 30 \\
\hline
\end{tabular}

Source: Food and Environmental Hygiene Department, HKSAR (2020)

To ease the demand, green burial has been launched and promoted by the HKSAR government through various print and social media. Such promotional ways and tools created a limited impact on the public awareness. Currently, scattering of cremains in Gardens of Remembrance or at sea are the two common ways to perform green burial. The public acceptance of green burial, however, is still a questionable issue as well as green burial is under-researched. To this end, our study is going to propose the adoption of innovative technology, namely virtual reality (VR) to improve physical and psychological fidelity in highly resembled scenarios for the people. On one hand, VR gives immeasurable value to people when they are enabled to navigate different circumstances (physical fidelity) before considering the use of green burial. On the other hand, VR enables the people to engage in different mental processes (psychological fidelity) replicated from an array of cognitive reaction and sentiments with the choice of green burial. [13, 14] In the study, we investigate: (1) To what extent the enhancement of physical fidelity of innovative technologies debunk public's misconception of green burial? (2) To what extent the enhancement of psychological fidelity of innovative technologies debunk public's misconception of green burial? (3) To what extent the simulation experience derived from innovation technologies change the public acceptance of green burial?
This paper is divided into six main parts. After the introduction in Section 1, we discuss the operation of handling human cremains in Section 2. In Section 3, we describe the research methodology. After that, we explore the concept of green burial and the current situation of green burial in Hong Kong in Section 4. The deployment of VR in green burial and conclusion are provided in Sections 5 and 6 , respectively.

\section{THE OPERATION OF HANDLING HUMAN CREMAINS}

\section{THE HANDLING OF DEATH FROM NATURAL CAUSES AND UNNATURAL CAUSES}

Starting from the case being created when a live body becomes human remains, the funeral operators need to identify or investigate that the death has been certified by a duty houseman in a hospital (i.e., natural cause) or unable to be certified by a duty houseman in a hospital (i.e., unnatural cause). At the beginning, the funeral operators are required to sort out the death from natural and unnatural causes for two main reasons. Firstly, all documents requirement and handling procedure are completed. Secondly, the Chinese traditional customs emphasize that the dead body should be in a quiet and calm environment where it fosters the soul to be free to go and return. 
All unnatural cases are required to be sent to a public mortuary to wait for dissection by a forensic doctor. The family of the deceased strives to avoiding the dissection because of their showing respect and love. This concept comes from Confucius - The Classic of Filial Piety: 'Our bodies, to every hair and bit of skin, are received by us from our parents. We must not presume to injure or wound them'.

According to the public health and municipal services ordinance (Hong Kong Law Chapter 132), the hospital houseman will issue a medical certificate for cremation once the case can be certified. It clearly describes that the deceased person was carefully examined that the death was not due to a poison, violence or any illegal operation or to privation or neglect the deceased person is fitted or not fitted with a cardiac pacemaker, and or with radioactive or other implant. The deceased person will be received for dissection in the place of public mortuary. Police and the coroner court will also be involved.

\section{THE ARRANGEMENTS OF CREMATION AND BURIAL}

In 2019, there were more than 120 licensed undertakers and 7 licensed funeral parlours in Hong Kong. [4] In some cases, religious venues are listed as the licensed funeral hall where it allows handling of human remains for its family of deceased. [5] $90 \%$ of the family of the deceased used cremation services with six public crematoria. Each crematorium needs to handle 21.6 cases per day in office hours. For the reason of saving money or keeping in a low profile, there is an increasing trend of families of the deceased selecting a short and simple farewell memorial rite with respect in a hospital's farewell room.

\section{RESEARCH METHODOLOGY}

In our study, we mainly employed a qualitative approach. Specifically, the researchers carried out 18 semi-structured, in-depth face-to-face interviews with the main personnel concerned with the development of green burial in Hong Kong. Due to confidentiality agreements, the interviewees' particulars are excluded in the study. The interviewees included funeral logistics firm, funeral service providers (e.g., cemeteries, funeral director), a religious group (e.g., Catholic, Priest, Christian, Pastor, Buddhist), health service professionals (e.g., rehabilitation therapist, elderly home), secondary school teacher (e.g., religious education), counselors, and general public (e.g., family of the deceased, boat people who is living on boats).

The interview questions focused on exploring the major consideration in choosing between green burial and traditional burial; further promotional strategies to increase the public awareness of green burial; and the simulation experience derived from innovation technologies (i.e., VR) (i.e., contents, special effects, layout design, and scenario) to change the public acceptance of green burial.

\section{THE CONCEPT OF GREEN BURIAL}

Since 2010, the concept of green burial has emerged in Hong Kong. Green burial aims to promote sustainable development and align with the beliefs of beautiful life returning to nature. [5] The Food and Environmental Hygiene Department (FEHD) performed green burial through scattering of cremains in Gardens of Remembrance or cremated ashes at sea. The FEHD has continuously expand green burial facilities and services in the last decade. Family of the deceased can select to scatter the cremated ashes of their loved ones at the Gardens of Remembrance themselves or with the aid of assigned staff of FEHD.

The documents and interviewees pointed out the rationale behind selecting green burial. The dramatic growth of population together with the scarce land resources in Hong Kong, increased the waiting time of public niche and burial. The interviewees highlighted that an average waiting time in Hong Kong for a public niche to hold cremated remains is four years. Funeral operator Kenneth Leung reinforced that the shortage in public niches would rise from 215,145 in 2019 to 398,145 in 2023 (South China Morning Post, 2016). The advancement of technology encourages delivering the green burial message more easily. To a certain extent, family members of the deceased perceived that they are a responsible and environmentally friendly citizen after using the green burial. The decreased family member expressed that green burial could help going back to the natural world (i.e., ashes to ashes, dust to dust) without posing any burden (time and financial). From the Buddhist perspective, we are connected whenever we go to the memorial garden. Trees and plants are gown well which is equivalent to a sense of belonging. 
The interviewees also highlighted that the family member will face the complex procedures when it compulsorily requires the removal of human remains from graves which have been interred in the public cemeteries for over six years. In the case of remains not exhumed after expiry of the exhumation order, the Government will, disinter them, cremate the remains and re-inter the ashes in the Communal Grave. [5] In other words, traditional burial creates a serious problem of unclaimed bodies. Besides, the migration problem and the distant relationships with the family and relative members lead the citizens to revisit and think about the use of green burial rather than traditional burial. Thus, the interviewees addressed that the green burial would make them more comfortable in the afterlife.

On the other hand, the green burial still fails to become mainstream and develops relatively slow progress. The public acceptance of green burial is still a questionable issue. In 2016, the Office of the Ombudsman criticized that the FEHD implemented an ineffective green burial serviced. In Table 2, the usage of green burial service between 2016 and 2018 is described.

TABLE 2: THE USAGE OF GREEN BURIAL SERVICE IN HONG KONG (2016-2018)

\begin{tabular}{|l|l|l|l|l|l|l|}
\hline YEAR & $\begin{array}{l}\text { SCATTERING OF } \\
\text { CREMAINS IN } \\
\text { GARDENS OF } \\
\text { REMEMBRANCE* }\end{array}$ & $\begin{array}{l}\text { SCATTERING } \\
\text { OF } \\
\text { CREMATED } \\
\text { ASHES AT } \\
\text { SEA }\end{array}$ & $\begin{array}{l}\text { TOTAL } \\
\text { NUMBER OF } \\
\text { GREEN } \\
\text { BURIAL } \\
\text { SERVICE* }\end{array}$ & $\begin{array}{l}\text { PERCENTAGE } \\
\text { OF TOTAL } \\
\text { DEATHS }\end{array}$ & $\begin{array}{l}\text { TOTAL } \\
\text { NUMBER OF } \\
\text { CREMATION }\end{array}$ & $\begin{array}{l}\text { TOTAL } \\
\text { NUMBER OF } \\
\text { BURIAL }\end{array}$ \\
\hline 2016 & 4466 & 900 & 5366 & $11.5 \%$ & 43556 & 3253 \\
\hline 2017 & 5573 & 966 & 6539 & $14.3 \%$ & 42809 & 2962 \\
\hline 2018 & 6074 & 972 & 7046 & $14.8 \%$ & 43803 & 3136 \\
\hline
\end{tabular}

Sources: Finance Committee, HKSAR (2019)

*Remark: The data includes private cemeteries

During the interview process, the majority of interviewees indicated that they do not understand the concept of green burial due to (1) ineffective promotional tools and channels; (2) a few of friends, and colleagues introduce the advantages of green burial service; and (3) a lack of communication between parents and children about death. Indeed, the interviewees highlighted that either scattering of cremains in Gardens of Remembrance or scattering of cremated ashes at sea make people perceived it to be in disrespect, frivolous, and easily forget to worship. Most importantly, the interviewees worried about the unprofessional manner in mixing up of their ashes with others will happen by FEHD in green burial operation.

Much of the reluctance is deeply rooted in tradition. From the Chinese traditional idea, green burial fails to preserve the whole-body afterlife and performs a 'shabby' funeral ceremony. The religious beliefs reinforce that we should respect the ashes of dead bodies. It is because from the Catholic and Christian perspective the Confirmation from the Holy Spirit, the body has become the Palace of the Holy
Spirit. Thus, the ashes should be stored and preserved in precious vessels. The ashes of the dead bodies are required to be buried in graves, mausoleums or ashes. It is not a respectable way to lay the ashes of the dead bodies on the sea, in the air, on the ground, and preserve them in the homes of family, relatives, and friends of the dead. In order to ease the shortage of niche and burial, Catholic Diocese of Hong Kong not only expands the land area of cemeteries, but also allows merging of the whole family member within the same niche or burial.

Furthermore, funeral logistics firm, funeral service providers expressed that the rise of green burial will affect the profit of the cemetery and coffins. In the traditional burial, the family of the deceased normally select solid wood coffin or fragrant wood coffin. The ranges of prices are between HKD 2 million and 3 million. In the green burial, eco-coffin will be charged from HKD 6,000 to HKD 0.2 million. Besides, some aspects (e.g., exhumation services) will gradually reduce and eventually lead to unemployment problem in the future. 


\section{DEPLOYMENT OF VIRTUAL REALITY (VR): GREEN BURIAL}

\section{DEVELOPMENT OF DESIGN OF VR}

The authors propose to deploy the green burial with VR: (1) The VR program not only will allow the public to experience the context under controllable conditions, but it will also provide a safe environment for them to understand green burial; (2) The program can be conducted repeatedly without the need to demonstrate with real situation that may be undesirable to the public; (3) It eliminates wasting of resources involved in real cases that meet the spirits of green; and (4) The VR program allows the simulated environment to provide a natural feeling.
Figure 1 illustrates the workflow of the deployment framework of the VR for green burial. In our development, the process is divided into 9 major steps as follows:

1. Investigation of green burial scenarios

2. Meeting with stakeholders to understand the details of green burial

3. Onsite visit and measurement for the green burial environment

4. Taking photos

5. Computer modelling

6. Assign texture and materials for the VR models

7. Computer programming in major VR Engine

8. Simulation of green burial scenarios

9. Testing and Evaluation

\section{FIGURE 1: THE WORKFLOW OF THE VR FRAMEWORK}

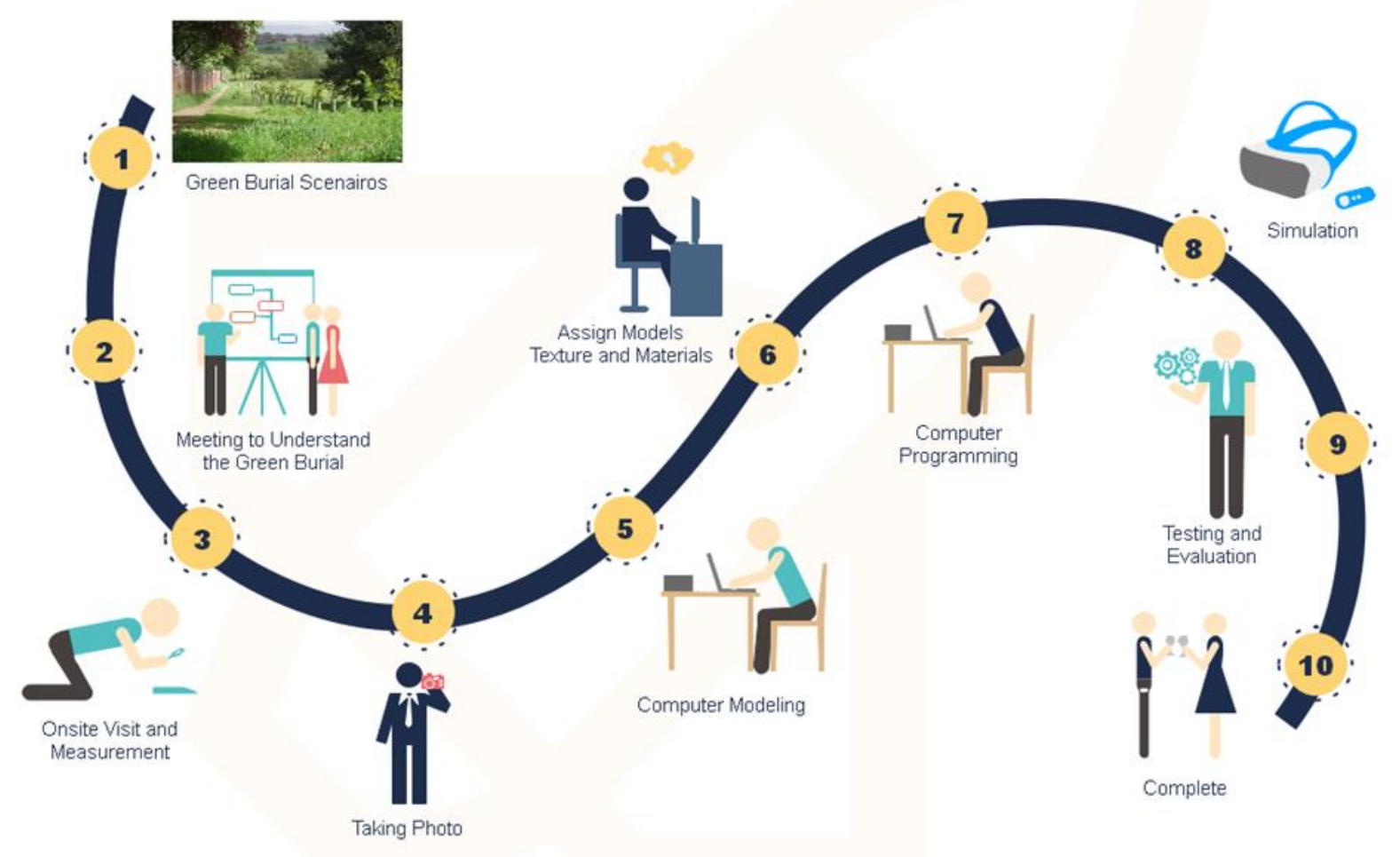



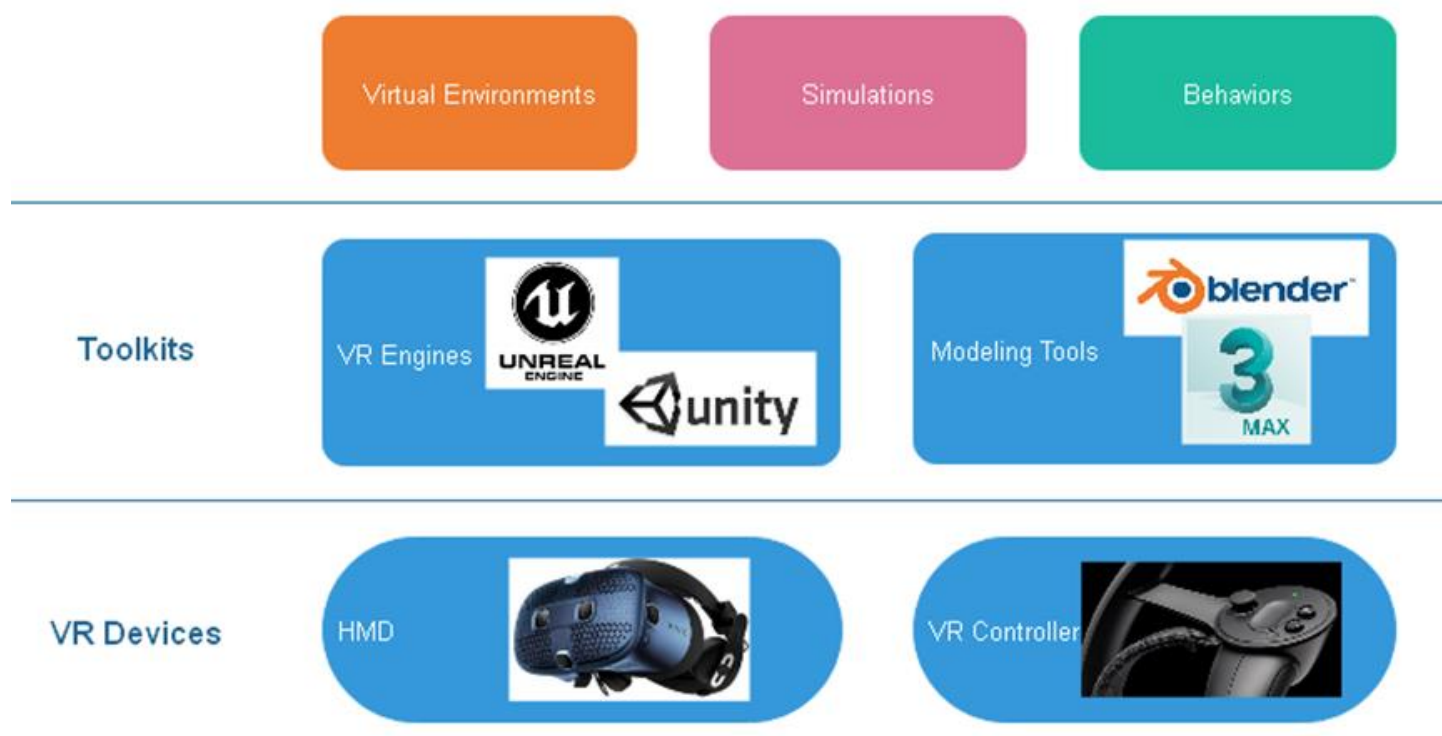

In this research, there are several key issues including content design, computer programming and project dissemination. In order to design the content, several steps are involved. The green burial scenarios are firstly formulated. The scenarios are used to deliver the green burial messages to the participants; thus, it should be welldesigned in the initial stage. For instance, the virtual environments and objects involved, what experiences to be delivered to the participants, any required interaction, to name but a few. Then, developers of the VR program are required to meet with the stakeholders in order to understand the expectations of the participants and other details of the green burial. To enhance the visual realism of virtual environments and objects in green burial in order to provide a realistic experience to the users, the developers are required to perform onsite visit, taking photos and measure the dimensions of real objects. Finally, computer modeling will be conducted to build the virtual environments and 3D objects involved in the VR program. Finally, lighting for the virtual scenes, materials and textures will be assigned to the 3D models for rendering.

After the content design is completed, computer programming will be conducted to create the VR experience for green burial. Computer programming is a technical part integrating the physical models, virtual objects into an immersive virtual reality system. Sensors and trackers are used to track the position and orientation in the virtual environment, so that participants can interact with the virtual environments if necessary. The system allows interaction between the virtual objects and participants in real-time. On the other hand, this procedure will also allow simulation of the inter-individual variation in the green burial scenario if necessary. Finally, in the project dissemination, simulation of various green burial scenarios will be conducted to investigate the effect of the VR program. We will conduct testing and evaluation on the VR program, and possibility of further improvement.

Figure 2 shows the block diagram of the VR program development. At the top layer of the VR development is some of the information that needs to be included in the program. It includes the virtual environments, simulation or animation to be included in the VR program, and the simulated behaviors of the virtual objects. At the middle layer, several software kits are required for the modeling and computer programming, common modeling toolkits include Blender, 3Ds Max, etc. Unreal and Unity are the most common engine for the development of the VR program.

The VR hardware includes the Head-mount display (HMD) and handheld controller. The HMD is used not only to provide stereoscopic images and audio effects to the user, but also used to determine the real-time orientation and position of the users. The real-time orientation and position are essential as it allows users to interact with the virtual objects by using the handheld controller if necessary. The devices will be connected to the computer through wireless network in order to stream the real-time scenarios and collect user's data for interactions. 


\section{PHYSICAL FIDELITY AND PSYCHOLOGICAL FIDELITY}

Currently, FEHD promotes green burial by using traditional promotional tools and channels, for instance, poster, video, leaflets, newspapers, TV programs, and website. During our interview process, most of the interviewees addressed that these promotional tools failed to persuade them to change their mindset from using traditional burial to green burial. The rationale behind is that they are unable to perceive the value of green burial through the process and understand how the green burial generates the peace, joy and dignity after the end of life. Through using VR, it can foster green burial that creates physical fidelity and psychological fidelity to make people understand the birth and death process.

The prevailing skepticism within the medical community towards VR as training tool led to low acceptance in the 90's. [6] The advancement of IT facilitates the adoption of $V R$ in healthcare and medical training and has been widely accepted with its positive impacts to improve patients' safety. [7] Previous studies showed that high-fidelity simulators improved users' understanding of a subject matter and led to better performance, such as reduction of the intraoperative errors [7] and learning effectiveness of medical students. [8] [9] The fidelity and resemblance simulated from the three-dimensional scenarios enable the physicians to assimilate their sensory responses and acquire skills in surgery and interventional cardiology.

Physical fidelity is defined as the degree of closeness that the conditions presented to users, such as physical settings or use of equipment mimic the authentic real contexts. [10] In the green burial VR simulation, users can experience the physical fidelity including the processes and embellishments involved in conventional cremation and green burial such as embalming chemicals to precipitate into the earth, carbon footprint of cremation. [11] The simulated context enables people to identity the association of green burial with sustainability and environmental-friendly practices.

Psychological fidelity is perceived as the extent of resemblance to which users are engaged in their mental and emotional processes under simulated situations mirroring the real world. [12,13,14] It is deemed that the messages or contexts presented to users, like the green burial, returning to nature in the proposed study can be delivered constantly and consistently. [7] Throughout the green burial VR simulation, users accommodate their cognitive processes in response to the images and scenes attesting to cemetery or memorial gardens, while their emotional stance can be examined further. Their responses on the simulated environment can be tracked and measured in order to evaluate the changes in their cognitive or emotional acceptance of green burial. [7]

\section{CONCLUSION}

In the context of the Hong Kong funeral industry, the funeral service providers strive towards offering comprehensive, one-stop and tailor-made service to customers. Every part of the funeral activities or tasks is planned with an immaculate attention to detail. It includes venue arrangement, government document processing, ceremony planning, venue decoration, music, and even obituary and eulogy writing. Additionally, grief counseling, reception arrangements, post-funeral services, and memorial activities will also be offered. To our best knowledge, the personal relationships with clients, word of mouth, and reputation remain the determining factors for the funeral service providers to gain funeral business.

Land availability is very limited, traditional burial services become an expensive and precious process. To this end, green burial is an optimal solution in solving the urgent demand for scarce land resources as well as providing an economical way to ease a financial burden. Besides, the funeral service users now rely on the information technologies to obtain the updated funeral information, explore the new knowledge, and participate in counseling service. In doing so, VR enhances physical fidelity and psychological fidelity of innovative technologies debunk public's misconception of green burial. In order to promote green burial by the deployment of VR, exploration of the right timing, appropriate promotional channels, and right people are crucial. In terms of right timing, FEHD can promote it during Chung Yeung Festival in October and Ching Ming Festival in April. Such two regular festivals are Hongkongers' customs to visit a grave. In terms of the right promotional channels, FEHD can collaborate with elderly home to give more information to the elderly and their parents/relatives. Also, FEHD attempts to engage with religious groups, secondary schools and tertiary institutions to deliver life education to address the value of green burial by the adoption of VR. Green burial may be appropriate to deliver a message to young generations, persons who take care of elderly, and the person who is eligible for senior citizen card (i.e., aged 65 or above). 
Because green burial is a new concept to the Hong Kong citizens, it is sensible that we need time to make the public gradually accept green burial by the VR deployment.

\section{References}

1. Lau YY, Chi, WK, Chan GHH. Procurement management in the private elderly home. CPCE Health Conference 2017; Hong Kong.

2. Chiu WK, Lau YY. Critical issues of pharmaceutical industry: A case study of recent advance in the chemical synthesis of Tamiflu. Int J of Drug Develop \& Res 2016; 8(3): 52-57.

3. Hong Kong Special Administrative Region. The Mortality Trend in Hong Kong (1986-2018). Hong Kong: Census and Statistics Department; 2019a.

4. Hong Kong Special Administrative Region.

Precautions for Handling and Disposal of Dead Bodies 2020. Available: < https://www.chp.gov.hk/files/pdf/grp-guideline-hp-icprecautions_for_handling_and_disposal_of_dead_bo dies_en.pdf> (Accessed 22/02/20)

5. Food and Environmental Hygiene Department, HKSAR. 2020. Available: < https://www.fehd.gov.hk/english/> (Accessed 15/02/20)

6. Satava RM. Virtual reality surgical simulator. Surg Endo 1993; 7(3): 203-205.

7. Gallagher AG, Cates, CU. Virtual reality training for the operating room and cardiac catheterisation laboratory. The Lan 2004; 364(9444): 1538-1540.

8. Littlewood KE, Shilling AM, Stemland CJ, Wright EB, Kirk MA. High-fidelity simulation is superior to case-based discussion in teaching the management of shock. Med Teach 2013; 35(3): e1003-e1010.

9. McGaghie WC, Issenberg SB, Petrusa ER, Scalese R J. A critical review of simulation-based medical education research: 2003-2009. Med Educ 2010; $44(1): 50-63$.

10. Greenberg JA, Blommer M. The Handbook of Driving Simulation for Engineering, Medicine and Psychology. United States: CRC Press; 2011

11. Vatomsky S. Thinking about having a 'green' funeral? Here's what to know 2018. Available: < https://www.nytimes.com/2018/03/22/smarterliving/green-funeral-burial-environment.html> (Accessed 20/02/20)

12. VirTra News. Keeping it real: physical \& psychological fidelity in use of force simulator training 2019. Available: <https://www.virtra.com/keeping-it-realphysical-psychological-fidelity-in-use-of-forcesimulator-training/> (Accessed 20/02/20)

13. Tang YM, Au KM, Leung Y. Comprehending products with mixed reality: Geometric relationships and creativity. Int J of Engineer Bus Manage 2018; 10: 1-12.

14. Tang YM, Au KM, Lau HCW, Ho, GTS, Wu, CH. Evaluating the effectiveness of learning design with mixed reality (MR) in higher education. Virt Real 2020; https://doi.org/10.1007/s10055-020-00427-9 